\title{
Application of metastatic biopsy based on "When, Who, Why, Where, How (4W1H)" principle in diagnosis and treatment of metastatic castration-resistance prostate cancer
}

\author{
Zihao Liu ${ }^{1,2 \#}$, Lei Wang ${ }^{2,3}$, Yuchi Zhou ${ }^{1,2}$, Chao Wang ${ }^{1,2}$, Yuan $\mathrm{Ma}^{2}$, Yang Zhao ${ }^{2,4}$, Jing Tian ${ }^{1,2}$, \\ Hua Huang ${ }^{1,2}$, Haitao Wang ${ }^{2,3}$, Yong Wang ${ }^{1,2}$, Yuanjie Niu ${ }^{1,2}$ \\ ${ }^{1}$ Department of Urology, The Second Hospital of Tianjin Medical University, Tianjin, China; ${ }^{2}$ Tianjin Institute of Urology, The Second Hospital \\ of Tianjin Medical University, Tianjin, China; ${ }^{3}$ Department of Oncology, The Second Hospital of Tianjin Medical University, Tianjin, China; \\ ${ }^{4}$ Department of Radiology, The Second Hospital of Tianjin Medical University, Tianjin, China \\ Contributions: (I) Conception and design: Z Liu, L Wang, Y Wang, Y Niu; (II) Administrative support: Y Zhao, Y Wang; Y Niu; (III) Provision of \\ study materials or patients: J Tian, H Wang, Y Wang, Y Niu; (IV) Collection and assembly of data: Z Liu, L Wang, Y Zhou, Y Zhao, J Tian, H \\ Huang, Y Wang, Y Niu; (V) Data analysis and interpretation: Z Liu, L Wang, C Wang, Y Ma, Y Wang, Y Niu; (VI) Manuscript writing: All authors; \\ (VII) Final approval of manuscript: All authors. \\ "These authors contributed equally to this work. \\ Correspondence to: Yuanjie Niu, MD, PhD; Yong Wang, MD, PhD. Department of Urology, The Second Hospital of Tianjin Medical \\ University, Tianjin 300211, China; Tianjin Institute of Urology, the Second Hospital of Tianjin Medical University, Tianjin 300211, China. \\ Email: yjniu9317@163.com; wy@tmu.edu.cn.
}

Background: To determine the feasibility of secondary biopsy of metastatic castration-resistance prostate cancer based on the " $4 \mathrm{~W} 1 \mathrm{H}-\mathrm{When}$, Who, Why, Where, How" principle and analyze the factors that affect tumor detection. Its application will further direct the patients for individualized precision therapy.

Methods: A total of 55 patients were collected for secondary biopsy (27 prostate biopsies and 55 metastases biopsies). The parameters of biopsy location, computed tomography attenuation coefficient, lesion size, core number, laboratory tests, and the use of bone protection were evaluated. Histopathological data and the pathogenesis and etiology classification were used to guide precision treatment.

Results: Fifteen/27 patients had a positive prostate biopsy, and 47/55 had positive metastasis biopsy. Bone metastasis biopsy was positive in 21/29 of cases. Also, parenchymal organs and lymph node biopsies were positive. In the prostate rebiopsy, significant differences were observed between total prostate volume $(\mathrm{P}=0.028)$, prostate-specific antigen (PSA) density $(\mathrm{P}=0.047)$, PSA velocity $(\mathrm{P}=0.036)$, and positive biopsy results. In the bone metastasis biopsy, we divided the patients into biopsy-positive and -negative groups. The computed tomography attenuation coefficient, PSA, alkaline phosphatase, and hemoglobin were related to tumor positive detection. However, the lesion size, core number, bone-sparing agents and previous treatments did not affect tumor detection.

Conclusions: In metastatic castration-resistant prostate cancer (mCRPC) patients, the " $4 \mathrm{~W} 1 \mathrm{H}$ " principle was applied in the second biopsy. The biopsy site, image, and laboratory variables affected the positive of tumor tissue. Further pathological analysis of tumor tissue is essential to guide the precision medicine of mCRPC etiological classification.

Keywords: Castration-resistant prostate cancer (CRPC); metastasis biopsy; bone; detection rate

Submitted Jan 11, 2021. Accepted for publication Mar 08, 2021.

doi: $10.21037 /$ tau-21-23

View this article at: http://dx.doi.org/10.21037/tau-21-23 


\section{Introduction}

Prostate cancer (PCa) is the first incidence and the second cause of mortality among malignant tumors in Western men (1). Due to the lack of prostate-specific antigen (PSA) screening in China, the diagnosed patients presented an advanced-stage disease. About $68 \%$ of the newly diagnosed PCa patients are already at the advanced stage (2). Although most patients are sensitive to androgen-deprivation therapy (ADT) at the beginning of treatment, after about 18 months, most patients gradually and irreversibly show castrationresistant prostate cancer (CRPC) (3). The therapeutic effect of metastatic castration-resistant prostate cancer (mCRPC) is poor because the current treatment decisions render it as a disease caused by a single mechanism. Therefore, the treatment of mCRPC has been challenging for clinicians (4). Thus, to improve the therapeutic effect, the pathogenesis underlying mCRPC needs to be elucidated, followed by classification for adequate treatment of the disease. This is plausible only by obtaining sufficient tumor tissue from mCRPC patients for pathological examination and further treatment.

However, some mCRPC patients had undergone radical prostatectomy, and prostate tissue could not be obtained. In such cases, only metastatic biopsy could be performed. Intriguingly, $\mathrm{PCa}$ is an osteophilic tumor, and up to $70 \%$ of PCa have bone metastasis $(5,6)$. PCa bone metastasis often causes intensive sclerotic reactions; hence, bone biopsies are technically challenging (7). Moreover, soft tissue metastasis is rare, and obtaining sufficient tumor tissue for molecular characterization is also challenging (7).

In order to improve the rate of acquiring tumors during sample collection, we need to develop a practical method that requires the cooperation of radiologists, pathologists, and urologists. Herein, we formulated the principle of "4W1H-When, Who, Why, Where, How" biopsy and utilized it clinically to decide the optimal time and site for tissue collection. This would aid in further classification of mCRPC in terms of etiology and adopting accurate medical methods for individualized treatment according to each subtype. We present the following article in accordance with the STROBE reporting checklist (available at http:// dx.doi.org/10.21037/tau-21-23).

\section{Methods}

\section{Patient population}

A total of $55 \mathrm{mCRPC}$ patients were selected from the
Second Hospital of Tianjin Medical University from July 2018 to July 2020. Patients were asked if they had histologically confirmed prostate adenocarcinoma, progressive disease despite "castration levels" of serum testosterone $[<50 \mathrm{ng} / \mathrm{dL}(1.73 \mathrm{nmol} / \mathrm{L})]$ with continued androgen-deprivation therapy and documented metastases, as confirmed by computed tomography (CT) or bone scanning with technetium-99m-labeled methylene diphosphonate. Patients must have three or more rising serum PSA values obtained at an interval of $\geq 2$ weeks, with the last value $>2.0 \mathrm{ng} / \mathrm{mL}$. The anterior gland biopsy and/ or metastatic biopsy were performed after obtaining the consent of the patient.

\section{Principles and procedures of biopsy}

Based on the basic research and clinical experience of longterm diagnosis and treatment of PCa and prostate biopsy, the biopsy principle of " $4 \mathrm{~W} 1 \mathrm{H}-$ when, who, why, where, how" was put forward to improve the detection rate of tumor tissue. When-in PCa patients treated with ADT for the first time, PSA increased for 3 consecutive weeks, which $>50 \%$ of the lowest value; testosterone reached the castration level of $<50 \mathrm{ng} / \mathrm{mL}$, and PSA $>2 \mathrm{ng} / \mathrm{mL}$ or imaging progress: bone scan detected more than two new bone lesions or soft tissue lesions enlarged as assessed by RECIST (8). The state of disease progression is best represented by the appearance of new lesions or new metastases (9). When the disease progresses, including PSA progression and new metastases presence, this is the best time for biopsy. Who-the patients diagnosed as CRPC with primary or metastatic lesions had Eastern Cooperative Oncology Group (ECOG) score $\leq 2$, and the predicted survival time exceeded 6 months. Why-at present, the limitation of mCRPC treatment guidelines and the blindness of treatment methods led to the poor effect of mCRPC treatment. In recent years, precision medicine has been accelerating into people's vision. Through next-generation sequencing (NGS), liquid biopsy, tissue biopsy and other techniques to describe the molecular characteristics of $\mathrm{mCRPC}$, and then bring new hope for the treatment of mCRPC. However, whether NGS or liquid biopsy is the preferred diagnostic method. Histopathological diagnosis by biopsy is still the gold standard. Moreover, the new lesions can represent the current state of disease progression. Therefore, the second biopsy of tumor tissue should be performed for the pathological diagnosis of mCRPC to achieve the purpose of accurate medical 
diagnosis and treatment. Where-for patient safety, according to the "seed and soil" theory of cancer metastasis and the "linear and branching" model of PCa metastasis (9), the second biopsy site was selected in the following order: visceral metastatic organ, lymph node, metastatic bone focus, and prostate. How-after the puncture site was determined, the biopsy needle was guided by ultrasound or real-time CT under local anesthesia. Ultrasound is suitable for thin patients with soft tissue lesions, such as abdominal organs or $\geq 1 \mathrm{~cm}$ lymph nodes, while CT is used in the vast majority of patients.

The biopsy site was preliminarily determined according to the imaging data of the patient and the " $4 \mathrm{~W} 1 \mathrm{H}$ " principle before the operation. The patient was placed in an appropriate body position, and the vital signs were monitored. Subsequently, 2\% lidocaine local infiltration anesthesia, routine disinfection, and towel laying was carried out. According to the biopsy site, the appropriate guidance technique, biopsy method, needle angle, and needle type were selected; metastasis or primary focus biopsy was performed under the guidance of CT or ultrasound, and real-time image was scanned. The change in the needle angle in real-time to obtain maximal tissue to reduce the complications. At the end of the biopsy, the puncture point was sterilized, covered with sterile gauze, and the wound was bandaged with an elastic bandage.

\section{Imaging and clinical variables}

Before bone metastasis biopsy, CT, and ${ }^{99 \mathrm{~m}} \mathrm{Tc}-\mathrm{methylene}$ diphosphonate bone scans were performed in all patients. The imaging data were analyzed by radiologists, urologists, and oncologists, and the following lesion variables were evaluated: (I) the location of the lesion; (II) the size of the lesion (length, width, and height); (III) the number of biopsies was determined according to the size, location, and subjective consciousness of the doctor; (IV) the quantitative attenuation coefficient defined by Hounsfield units (HU) was rounded to an integer. The quantitative attenuation coefficient was calculated by the average value of three measurements at the biopsy site. The size of the lesion was determined by the average value of the maximum value measured three times at the biopsy site.

Baseline demographic, clinical, and laboratory data, including age, biopsy site, PSA, PSA density (PSAD),
PSA velocity (PSAV), PSA double time (PSADT), alkaline phosphatase (ALK), hemoglobin (HGB), previous treatment (hormonal therapy, chemotherapy, radiotherapy, and prostatectomy), and use of bone protective agents, were collected. The total prostate volume (TPV) was calculated according to the following formula: TPV = $0.523 \times$ transverse diameter $(\mathrm{cm}) \times$ anterior diameter $(\mathrm{cm}) \times$ posterior diameter $(\mathrm{cm}) \times$ longitudinal diameter $(\mathrm{cm})$.

\section{Tissue specimen management and patbological diagnosis}

CRPC prostate and/or metastatic tissues were fixed in $10 \%$ formalin solution for $24 \mathrm{~h}$. Then, paraffin-embedded wax blocks were prepared, and $5-\mu \mathrm{m}$ anti-exfoliation sections were sliced for hematoxylin-eosin (HE) and immunohistochemistry (IHC) staining. If necessary, the excess tissue can be stored in the tissue-protective solution for NGS. Among these, bone tissue specimens require a surface or routine decalcification. The bone biopsy was sealed in a container filled with $10 \%$ parafilm solution and fixed with agitation at room temperature for 24-30 h. After the sample was fixed, it was briefly washed in distilled water, placed in a container of EDTA solution, sealed, and incubated at $37^{\circ} \mathrm{C}$ for $48 \mathrm{~h}$. All the pathological procedures were completed by two senior pathologists separately. If tumor cells were detected in HE staining, the biopsy results were recorded as positive.

\section{Statistical analysis}

SPSS version 24.0 and GraphPad Prism version 8.0.1 software were used for statistical analysis. The enumeration data were expressed in terms of rate (\%), the inter-group rates were compared by chi-square test and Fisher's exact test, and the measurement data were analyzed by $t$-test and expressed as mean \pm standard deviation $(\mathrm{SD})$. A $\mathrm{P}$ value $\leq 0.05$ indicated a significant difference.

\section{Ethics}

This study was approved by the Ethical Review Board of the Second Hospital of Tianjin Medical University (registration number KY2019K091 and KY2018K048) and carried out in accordance with the principles outlined in the Declaration of Helsinki (as revised in 2013). Informed consent was 
Table 1 Biopsy site statistics

\begin{tabular}{lccc}
\hline Site & Total & Positive, $\mathrm{n}(\%)$ & Negative, $\mathrm{n}(\%)$ \\
\hline Primary tumor (prostate) & 27 & $15(55.56)$ & $12(44.44)$ \\
Metastasis & 55 & $47(85.45)$ & $8(14.55)$ \\
Bone & 29 & $21(72.41)$ & $8(27.59)$ \\
Lymph nodes & 13 & $13(100.00)$ & $0(0.00)$ \\
Parenchyma organ & 13 & $13(100.00)$ & $0(0.00)$ \\
Liver & 7 & $7(100.00)$ & $0(0.00)$ \\
Lung & 3 & $3(100.00)$ & $0(0.00)$ \\
Kidney or adrenal gland & 2 & $2(100.00)$ & $0(0.00)$ \\
Pelvic mass & 1 & $1(100.00)$ & $0(0.00)$ \\
\hline
\end{tabular}
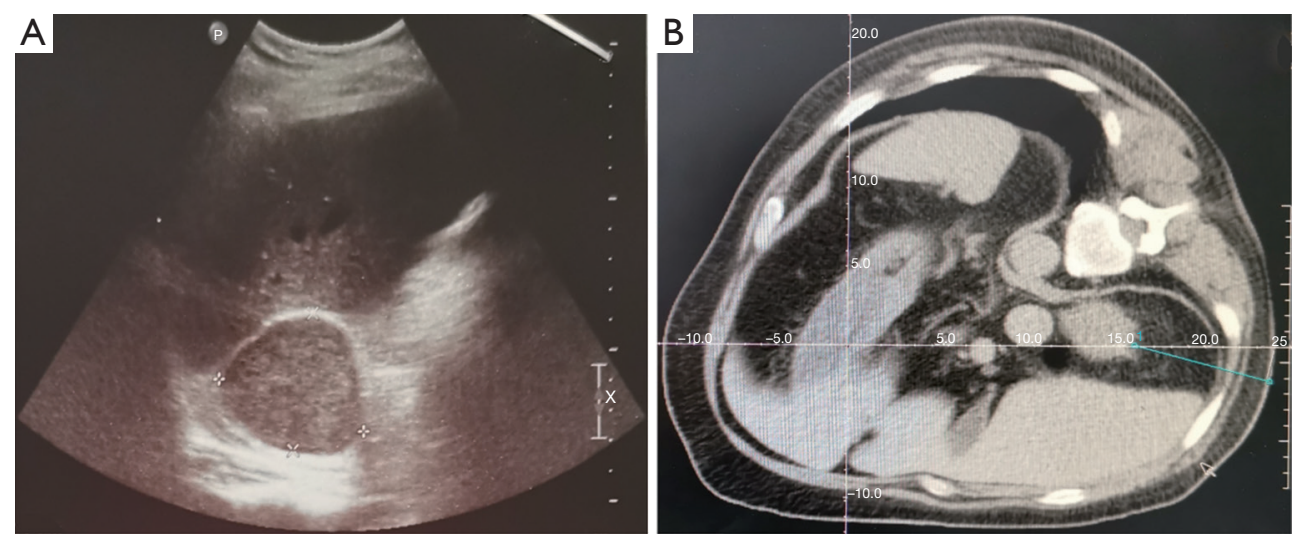

Figure 1 Images of the adrenal gland with different imaging techniques. (A) B-ultrasound and (B) fluoroscopic images of the adrenal gland under CT examination. The biopsy results are sufficient for pathological examination.

obtained from each patient in this study.

\section{Results}

\section{Biopsy sites and pathological results}

A total of 55 mCRPC patients, including 27 cases of prostate biopsy and 55 cases of metastatic biopsy (29 cases of bone biopsy, 13 cases of lymph nodes, 13 cases of parenchymal organs, 7 cases of liver, 3 cases of lung, 2 cases each of kidney and adrenal gland, and 1 case of pelvic mass), underwent secondary biopsy (Table 1). Prostate biopsies were positive in $15(55.56 \%)$ cases. Metastatic biopsies were positive in $47(85.45 \%)$ cases, and negative in 8 metastatic bone cases. The positive rate showed a significant difference between the prostate and metastatic biopsy $(\mathrm{P}=0.003)$. Further analysis revealed significant differences in the positive rate among the three biopsy sites of bone, lymph nodes, and parenchyma organs $(\mathrm{P}=0.015)$. Next, we enumerated the fluoroscopic images of different tissues under various guidance techniques (Figures 1-3).

\section{Influence of biopsy parameters on the positive rate of diagnosis}

The average age of prostate biopsy positive group was $70.93 \pm 5.74$ years, and that of the negative group was $69.58 \pm 8.01$ years (Table 2). Strikingly, 11/27 (40.74\%) cases were treated with chemotherapy, and 8/27 (29.63\%) cases were treated with radiotherapy. For prostate biopsy, the biopsy results were not related to age, PSA, PSADT, location of metastatic lesions, and previous therapeutic schedule (Table 2). However, TPV, PSAD, and PSAV were 

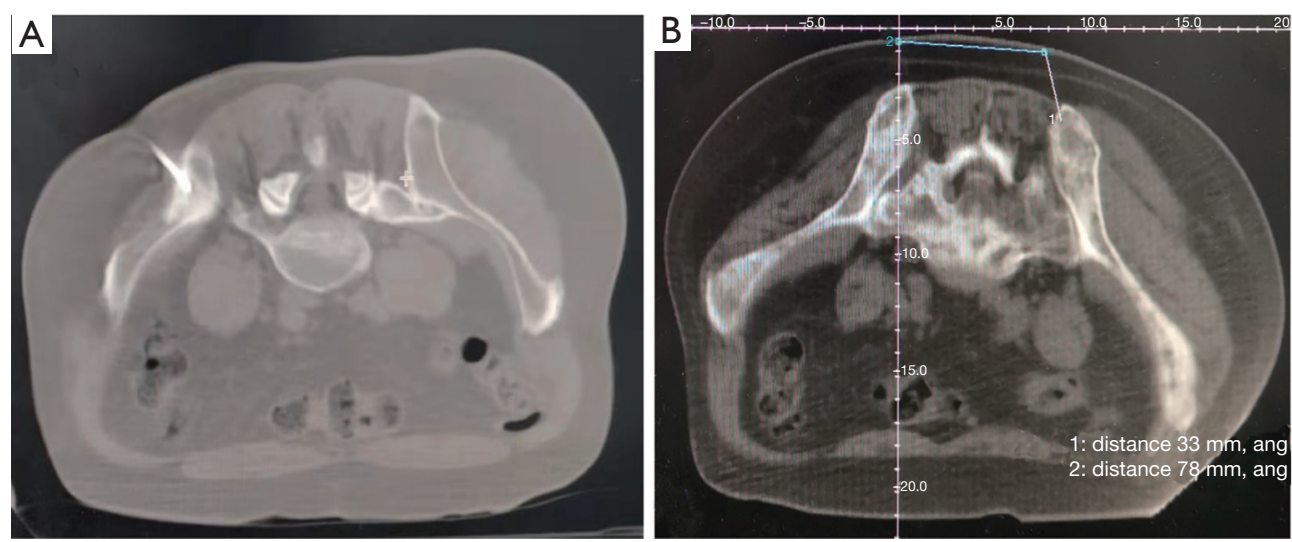

Figure 2 Computed tomography (CT) images of bone tumors with different degrees of change. (A) The osteogenic changes and (B) the osteolytic changes fluoroscopic images of the bone metastases under CT examination. The biopsy results are sufficient for pathological examination.

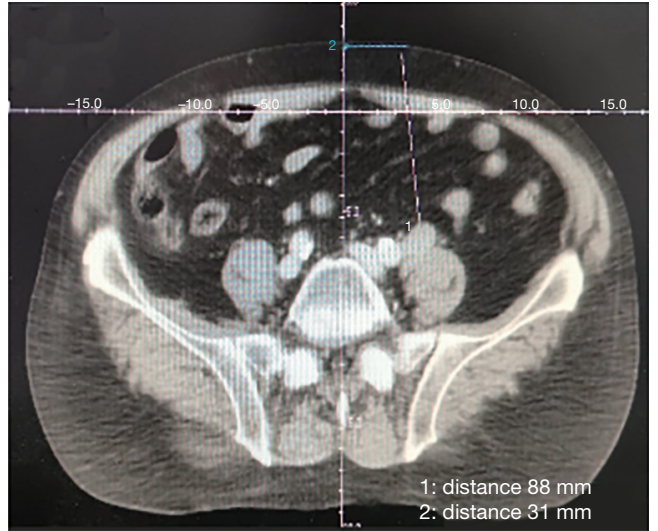

Figure 3 The fluoroscopy image of lymph nodes under computed tomography (CT) examination. The biopsy results are sufficient for pathological examination.

significantly correlated with the results of biopsy $(\mathrm{P}=0.028$, $\mathrm{P}=0.047, \mathrm{P}=0.036$ ) (Figure 4).

The average age of the bone biopsy positive group was $69.57 \pm 6.76$ years, and that of the negative group was $67.13 \pm 5.30$ (Table 3). A total of 20/29 (68.97\%) cases were treated with bone protective agents. The median duration of treatment was 10 months, and most of the patients have symptoms of anemia. Typically, the biopsy results of bone metastases were similar irrespective of age, lesion size, the use of bone-sparing agents, and the choice of previous therapeutic schedule (Table 3). However, the laboratory examinations revealed that the level of PSA, ALK, and HGB was significantly correlated to the biopsy results of bone metastases $(\mathrm{P}=0.039, \mathrm{P}<0.001$, and $\mathrm{P}=0.036)$.
Among the imaging variables, a significant correlation was established between $\mathrm{CT}$ attenuation and the biopsy results $(\mathrm{P}=0.019)$ (Table 3 and Figure 5).

\section{Etiological classification and efficacy of individualized precision therapy of CRPC}

Based on previous studies and literature review, we put forth three types of mechanisms for the formation of CRPC (10-12): (I) androgen receptor (AR)-related mechanisms; (II) stem cell formation mechanisms; (III) neuroendocrine transformation mechanisms. According to the heterogeneity, diversity, and the formation mechanism, the etiology of CRPC was classified, and individualized precision medicine administered. CRPC was divided into three types as follows: type I: AR signal-dependent, the molecular marker was FKBP5, and abiraterone (Abi) + prednisone was given; type II: tumor stem cell, the molecular marker was YAP1, and targeted therapy was given; type III: neuroendocrine, the molecular marker was NTS, and docetaxel + carboplatin was administered (13).

A total of 55 mCRPC were included in this study. Table 4 showed the typing results of some patients. We also launched Asia's first umbrella clinical trial for precision medicine of advanced PCa. The preliminary results showed that according to the different characteristics of drug resistance, individualized treatment with CRPC gained a definite effect (14). Next, we administered Abi and prednisone to one AR signal-dependent mCRPC patient with FKBP5(+) phenotype, and another stem cell mCRPC patient with AR(+) YAP1(+) phenotype received 
Table 2 Effect of biopsy parameters on diagnostic yield (prostate biopsy)

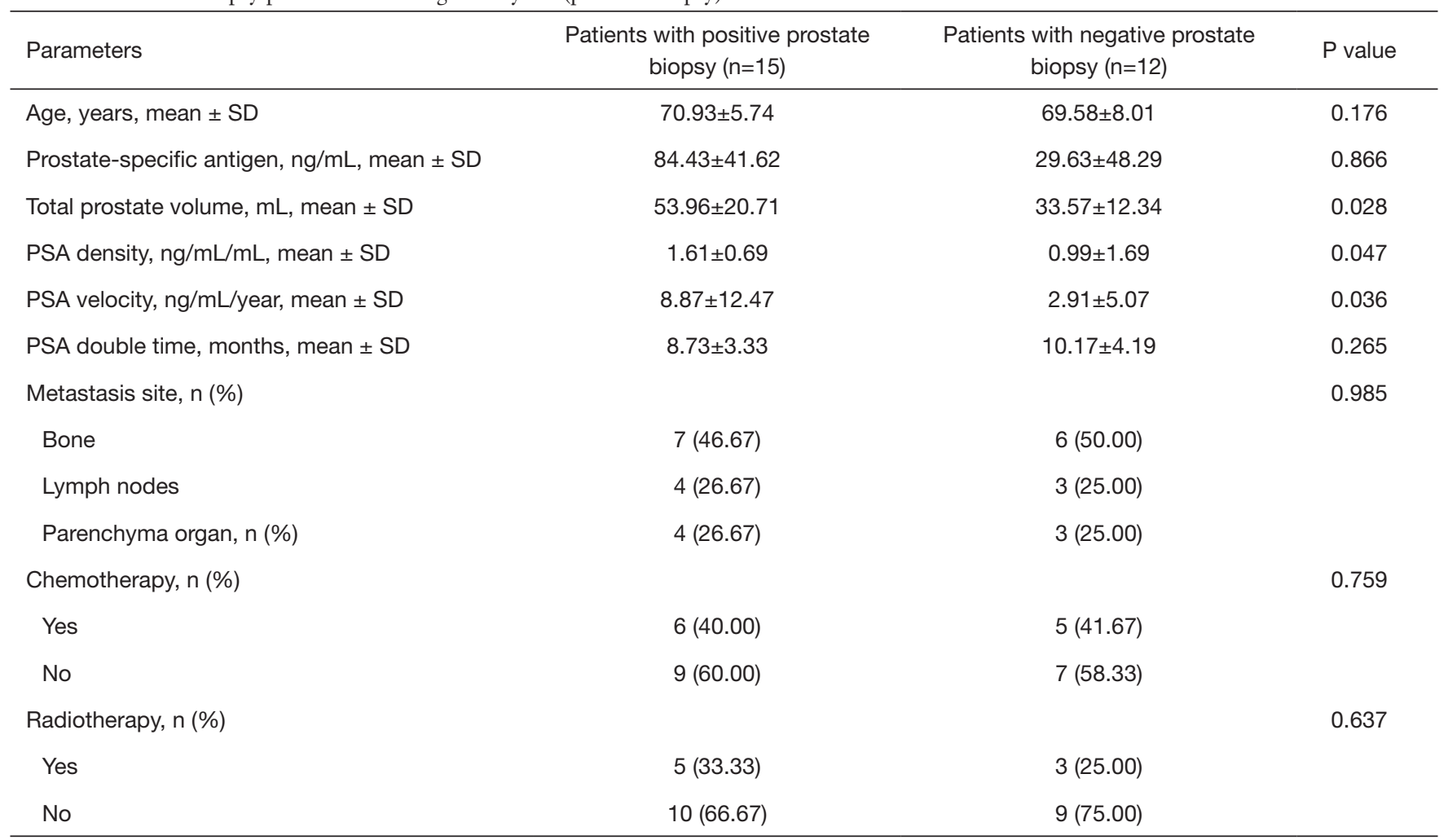

$\mathrm{SD}$, standard deviation.
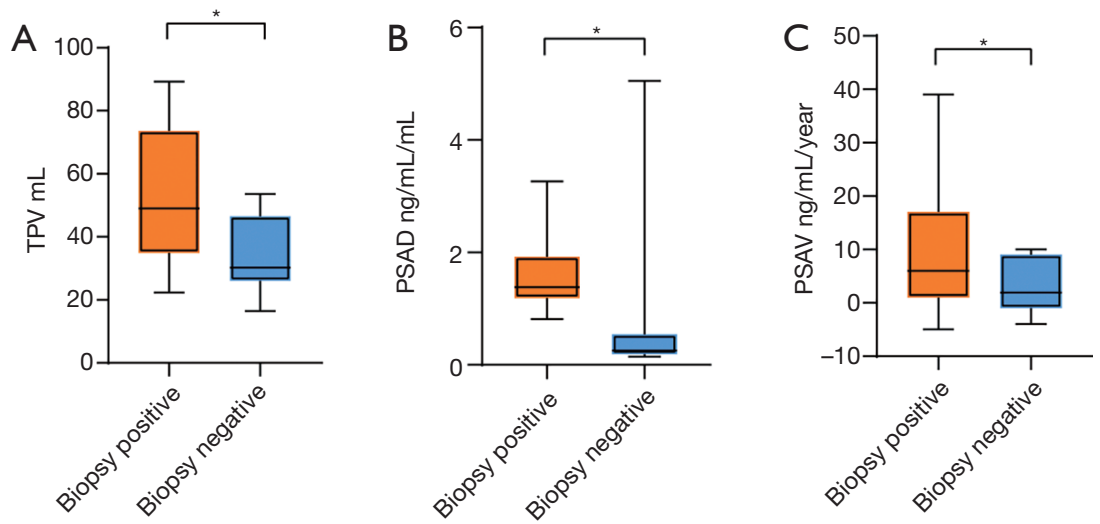

Figure 4 Box-and-whisker plot shows mean the results of the total prostate volume (TPV) (A), PSA density (PSAD) (B), and PSA velocity $(\mathrm{PSAV})(\mathrm{C})$. Differences in these parameters between positive and negative biopsy groups were significant (respectively, $\mathrm{P}=0.028, \mathrm{P}=0.047$, $\mathrm{P}=0.036) .{ }^{*}, \mathrm{P}<0.05$.

the same treatment. The progression-free survival (PFS) of two patients was 14 and 11 months, respectively. Also, 4 neuroendocrine mCRPC patients received chemotherapy of CD regimen (docetaxel and carboplatin), and satisfactory results were obtained (Table 5).

\section{Discussion}

The prognosis of CRPC is poor, and the survival time is about 12 months (15). Metastasis, especially bone metastasis, is common in CRPC patients (16). The living 
Table 3 Effect of biopsy parameters on diagnostic yield (bone biopsy)

\begin{tabular}{|c|c|c|c|}
\hline Parameters & $\begin{array}{l}\text { Patients with positive bone } \\
\text { biopsy }(n=21)\end{array}$ & $\begin{array}{l}\text { Patients with negative bone } \\
\text { biopsy }(n=8)\end{array}$ & $P$ value \\
\hline Age, years, mean $\pm S D$ & $69.57 \pm 6.76$ & $67.13 \pm 5.30$ & 0.477 \\
\hline Hemoglobin, g/dL, mean \pm SD & $106.05 \pm 15.07$ & $127.50 \pm 5.37$ & 0.036 \\
\hline Lesion size, $\mathrm{cm}$, mean $\pm \mathrm{SD}$ & $2.33 \pm 1.02$ & $2.39 \pm 0.72$ & 0.097 \\
\hline Core number, mean $\pm \mathrm{SD}$ & $2.10 \pm 0.70$ & $2.13 \pm 0.35$ & 0.096 \\
\hline Bone-sparing, $\mathrm{n}(\%)$ & & & 0.665 \\
\hline Yes & $15(71.43)$ & $6(75.00)$ & \\
\hline No & $6(28.57)$ & $2(25.00)$ & \\
\hline Radiotherapy, n (\%) & & & 0.461 \\
\hline Yes & $5(23.81)$ & $3(37.50)$ & \\
\hline No & $16(76.19)$ & $5(62.50)$ & \\
\hline
\end{tabular}

SD, standard deviation.
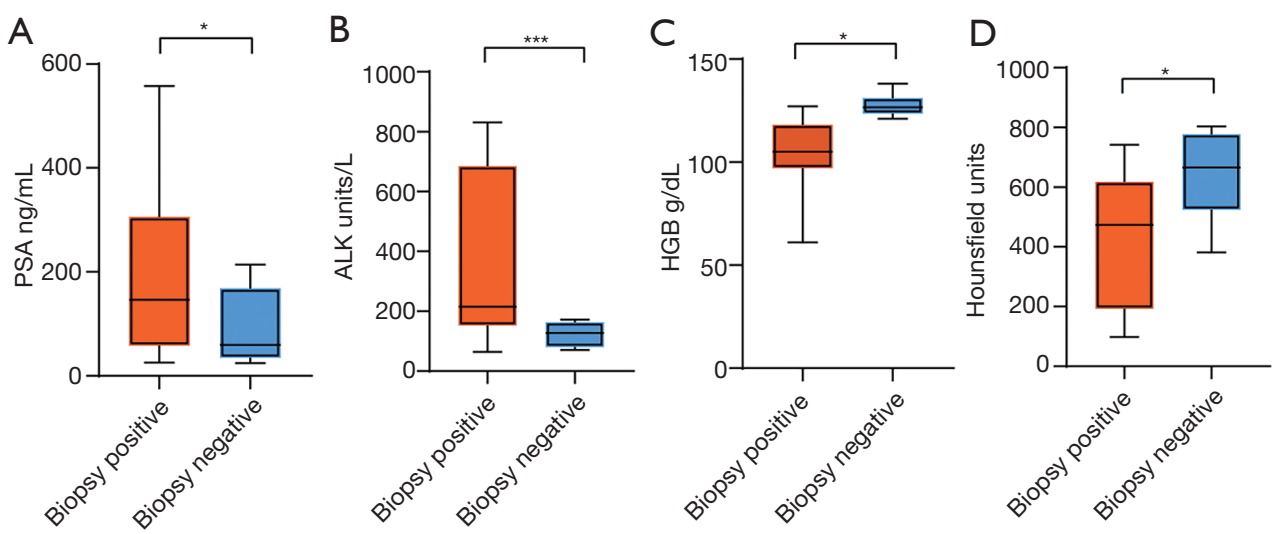

Figure 5 Box-and-whisker plot shows the results of the prostate-specific antigen (PSA) (A), alkaline phosphatase (ALK) (B), hemoglobin (HGB) (C) and CT attenuation values (D). Differences in these parameters between positive and negative biopsy groups were significant (respectively, $\mathrm{P}=0.039, \mathrm{P}<0.001, \mathrm{P}=0.036, \mathrm{P}=0.019)$. *, $\mathrm{P}<0.05$; *** $\mathrm{P}<0.001$.

quality of most patients is low. Although there are several guidelines for the diagnosis and treatment of CRPC, the scope of application and benefit for patients is limited. Moreover, a high degree of heterogeneity was detected between primary PCa and advanced CRPC, and different individuals exhibited molecular characteristics at various stages. Therefore, secondary biopsies are essential to obtain tumor tissues for pathological analysis, etiological classification, and NGS. Based on the pathological analysis and mechanisms of CRPC, we carried out individual 
Table 4 The results of etiological typing of some CRPC

\begin{tabular}{|c|c|c|c|c|c|c|}
\hline Patients & Medical record number & Biopsy site & Histopathological results & FKBP5 & NTS & YAP \\
\hline No. 2 & 474982 & Lymph nodes & Lymph node metastatic prostate cancer & - & + & - \\
\hline No. 3 & 474955 & Bone & Metastatic prostate cancer of bone & + & - & - \\
\hline No. 4 & 477505 & Bone & Benign bone tissue & - & - & - \\
\hline No. 6 & 480586 & Lung & Lung metastatic prostate adenocarcinoma & + & - & - \\
\hline No. 7 & 482279 & Bone & Metastatic prostate cancer of bone & - & - & + \\
\hline \multirow[t]{2}{*}{ No. 8} & \multirow[t]{2}{*}{483156} & \multirow{2}{*}{$\begin{array}{l}\text { Prostate Lymph } \\
\text { nodes }\end{array}$} & Prostate adenocarcinoma & \multirow[t]{2}{*}{-} & \multirow[t]{2}{*}{-} & \multirow[t]{2}{*}{-} \\
\hline & & & Lymph node metastatic prostate cancer & & & \\
\hline No. 11 & 486174 & Lymph nodes & Lymph node metastatic prostate cancer & + & - & - \\
\hline No. 12 & 487124 & Prostate/Bone & Changes after prostate endocrine therapy Benign bone tissue & - & - & + \\
\hline No. 13 & 490816 & Bone & Metastatic prostate cancer of bone & + & + & - \\
\hline No. 14 & 491016 & Lymph nodes & Lymph node metastatic prostate cancer & + & - & + \\
\hline No. 15 & 494558 & Lung & Lung metastatic prostate adenocarcinoma & - & - & - \\
\hline No. 16 & 494535 & Bone & Benign bone tissue & + & - & - \\
\hline
\end{tabular}

CRPC, castration-resistant prostate cancer.

Table 5 The curative effect of individualized precision treatment of partial CRPC

\begin{tabular}{|c|c|c|c|c|c|c|c|}
\hline Patients & $\begin{array}{l}\text { Secondary biopsy } \\
\text { pathology }\end{array}$ & $\begin{array}{l}\text { Immunohistochemical } \\
\text { staining }\end{array}$ & $\begin{array}{l}\text { Therapeutic } \\
\text { scheme }\end{array}$ & $\begin{array}{l}\text { Follow-up time } \\
\text { (month) }\end{array}$ & $\begin{array}{l}\text { Therapeutic } \\
\text { evaluation }\end{array}$ & $\begin{array}{l}\text { Adverse } \\
\text { reaction }\end{array}$ & $\begin{array}{c}\text { PFS } \\
\text { (month) }\end{array}$ \\
\hline No. 3 & $\begin{array}{l}\text { Metastatic prostate } \\
\text { cancer of bone }\end{array}$ & FKBP5(+) & $\begin{array}{l}\text { Abiraterone + } \\
\text { prednisone }\end{array}$ & 20 & PR, PSA decrease & Edema & 14 \\
\hline No. 12 & $\begin{array}{l}\text { Changes after prostate } \\
\text { endocrine therapy }\end{array}$ & $\mathrm{CgA}(+), \mathrm{YAP}(+)$ & $\begin{array}{l}\text { Docetaxel + } \\
\text { carboplatin }\end{array}$ & 16 & PR, PSA decrease & Nausea, vomiting & 12 \\
\hline No. 29 & $\begin{array}{l}\text { Prostatic adenocarcinoma } \\
\text { with NED }\end{array}$ & $\operatorname{CgA}(+), \operatorname{Syn}(+), A R(+)$ & $\begin{array}{l}\text { Docetaxel + } \\
\text { carboplatin }\end{array}$ & 10 & PSA decrease & Fatigue, anemia & 6 \\
\hline No. 37 & $\begin{array}{l}\text { Metastatic prostate } \\
\text { cancer of liver }\end{array}$ & NTS(+) & $\begin{array}{l}\text { Docetaxel + } \\
\text { carboplatin }\end{array}$ & 12 & PR & Anorexia, anemia & 9 \\
\hline
\end{tabular}

CRPC, castration-resistant prostate cancer; PFS, progression-free survival; PR, progesterone receptor; PSA, prostate-specific antigen. 
precision medicine for patients. In view of high-quality tissue acquisition, the challenges of biopsy techniques, and the complexity of previous treatment, we analyzed factors that may improve the tumor detection rate of secondary biopsies. This analysis laid the foundation for the collection of high-quality organizations aiming to characterize mCRPC tumors to direct individual precision medicine.

According to the economy and convenience, we conducted a prostate rebiopsy, but the positive rate was not satisfactory. Subsequently, we found that TPV, PSAD, and PSAV affect the results of a prostate biopsy. The previous findings (17-19) were consistent with our results. Several mCRPC patients had undergone radical prostatectomy, and we could not do a second prostate biopsy.

The metastasis of PCa supports the "seed and soil" theory and the "linear and branching" model of PCa metastasis (9). The tumor spreads in multiple places and forms and is termed as "metastasis to metastasis". The current results showed that the biopsy site affected the tumor detection positive rate, and metastatic tissue biopsies could detect tumor cells easily. After endocrine therapy, the original endocrine therapy - sensitive PCa developed into CRPC. The pathological morphology of CRPC prostate tissue altered significantly and manifested as the decrease in the volume and density of adenocarcinoma foci, the increase in scattered interacinar matrix, and atrophy and apoptosis of cancer foci, affecting the grading judgment; however, the expression of cancer markers could be detected (20-22). The biopsy site of metastatic foci also had an impact on the diagnosis of tumors. Tumor cells were detected easily in parenchyma organs and lymph nodes, but that of bone metastasis was not satisfactory. Supposedly, the metastatic foci of soft tissue and parenchyma organs were large and easy to obtain and could improve the detection rate of tumors (23). However, solid organ soft tissue metastasis is rare in mCRPC, and bone metastasis is common. There are two main types of bone metastasis, one characterized by bone destruction and the other characterized by new bone formation (24). Bone metastasis of PCa is usually osteogenic change, accounting for up to $95 \%$, and about $5 \%$ of patients are mixed type; simple osteolytic destruction is rare in clinical settings (25). This renders difficulty in obtaining bone tissue and the complexity of the tissue processing procedure.

The strategy to improve the tumor yield of mCRPC bone biopsy has been limited. The largest study, a clinical trial of 26 centers with 184 mCRPC participants showed that the positive rate of non-image-guided bone biopsies was only $25.5 \%$ (26). In another study, 54 image-guided biopsies were performed on $31 \mathrm{mCRPC}$, and $67 \%$ of the specimens were found to be histologically positive (27). Brown et al. (28) used bone scanning to guide bone biopsy and compared the bone tissue biopsy of 20 patients with mCRPC with a positive rate of $75 \%$.

When the bone biopsy was performed, the imaging examination was carried out in advance, while the second biopsy was carried out under the guidance of CT. The largest lesion of the site for biopsy was selected, such that we could use core numbers to obtain sufficient tissue. Nonetheless, the current study did not confirm that the core number of biopsies could increase the detection rate of tumors. Moreover, a previous study reported that only three cores are required to maximize bone biopsy yields. In addition, we did not find a correlation between lesion size and tumor detection, which was not consistent with previous studies (7). This phenomenon could be attributed to the small number of patients and limited lesions. Combined with previous studies, we deduced that the nature of bone tissue lesions reduces the acquisition of tissue and the detection rate (28). Furthermore, this study established a correlation between CT attenuation coefficient and tumor detection. The patients with lower attenuation had a higher detection rate of bone tumors. In a bone biopsy study of 410 patients, a correlation was established between imaging findings and detection accuracy (29), which was consistent with our findings.

Herein, we hypothesized that the clinical parameters associated with a high disease burden could increase the detection rate of tumors, including the location of the disease, an increase in PSA and ALK, and a decrease in HGB. In a clinical study involving 194 patients, univariate analysis showed that low HGB and high ALK and PSA levels were associated with tumor detection (26), which was consistent with our results. In addition, patients with abnormal laboratory data presented a severe disease.

Since $\mathrm{PCa}$ is an osteophilic tumor, patients are prone to skeletal-related events that could be treated with bonesparing agents. We hypothesized that the use of these agents reduces the detection of tumors and increase bone sclerosis, thereby reducing tissue acquisition and tumor detection $(23,27)$. However, the current results did not achieve a similar conclusion. This phenomenon might be related to less bone destruction and fewer patients using bonesparing agents in our group. Nevertheless, the present study had several limitations. Although samples were collected prospectively, we conducted a retrospective analysis of 
imaging data and laboratory examinations. In addition, the sample size was small, resulting in differences in the analysis of variables. Deviation in the selection of biopsy sites, the determination of lesion size, and the grasp of biopsy direction were observed. Also, our analysis of the factors affecting tumor detection may not be comprehensive. The pathological examination of bone tissue needs specific treatment, and there may be some deviation in the interpretation of the results. These factors might affect tissue acquisition and tumor detection.

In terms of complications, second biopsy may cause the risk of bleeding, infection, lumbago, fracture, pneumothorax, and even implant metastasis. However, none of the 55 patients we did biopsy had serious complications. Only 1 patient developed lumbago after lumbar biopsy, which may be related to neuro-edema caused by biopsy. After treatment, the symptoms were relieved 3 months later.

In conclusion, with the development of precision medicine, CRPC has entered a new era of individual precision therapy. The application of " $4 \mathrm{~W} 1 \mathrm{H}$ " principle to obtain secondary biopsy tissue not only reduces the difficulty of biopsy and the complications but also obtains sufficient tissue and improves the detection rate of the tumor. Thus, typing therapy based on etiology and secondgeneration gene sequencing could be carried out to screen the main mutant genes of CRPC, in order to treat CRPC effectively.

\section{Acknowledgments}

We would like to thank the researchers and study participants for their contributions.

Funding: This work was supported by the National Natural Science Foundation of China (grant numbers 91959114 and 81872106), and The Second Hospital of Tianjin Medical University Clinical Medicine Research Project (grant number 2018KYLC007 and 2019LC02).

\section{Footnote}

Reporting Checklist: The authors have completed the STROBE reporting checklist. Available at http://dx.doi. org/10.21037/tau-21-23

Data Sharing Statement: Available at http://dx.doi. org/10.21037/tau-21-23

Conflicts of Interest: All authors have completed the ICMJE uniform disclosure form (available at http://dx.doi. org/10.21037/tau-21-23). The authors have no conflicts of interest to declare.

Ethical Statement: The authors are accountable for all aspects of the work in ensuring that questions related to the accuracy or integrity of any part of the work are appropriately investigated and resolved. This study was approved by the Ethical Review Board of the Second Hospital of Tianjin Medical University (registration number KY2019K091 and KY2018K048) and carried out in accordance with the principles outlined in the Declaration of Helsinki (as revised in 2013). Informed consent was obtained from each patient in this study.

Open Access Statement: This is an Open Access article distributed in accordance with the Creative Commons Attribution-NonCommercial-NoDerivs 4.0 International License (CC BY-NC-ND 4.0), which permits the noncommercial replication and distribution of the article with the strict proviso that no changes or edits are made and the original work is properly cited (including links to both the formal publication through the relevant DOI and the license). See: https://creativecommons.org/licenses/by-nc-nd/4.0/.

\section{References}

1. Siegel RL, Miller KD, Jemal A. Cancer statistics, 2020. CA Cancer J Clin 2020;70:7-30.

2. Ren $\mathrm{S}, \mathrm{Xu} \mathrm{J}$, Zhou T, et al. Plateau effect of prostate cancer risk-associated SNPs in discriminating prostate biopsy outcomes. Prostate 2013;73:1824-35.

3. Thomas C, Lamoureux F. Systemic treatment of bone metastases in castration-resistant prostate cancer (CRPC): pre-clinical to clinical point of view. Bone Cancer (Second edition), 2015:637-46.

4. Cornford P, Bellmunt J, Bolla M, et al. EAU-ESTROSIOG Guidelines on Prostate Cancer. Part II: Treatment of Relapsing, Metastatic, and Castration-Resistant Prostate Cancer. Eur Urol 2017;71:630-42.

5. Logothetis CJ, Lin SH. Osteoblasts in prostate cancer metastasis to bone. Nat Rev Cancer 2005;5:21-8.

6. Coleman RE, Rubens RD. The clinical course of bone metastases from breast cancer. Br J Cancer 1987;55:61-6.

7. Wu JS, Goldsmith J, Horwich P, et al. Bone and softtissue lesions: what factors affect diagnostic yield of imageguided core-needle biopsy? Radiology 2008;248:962-70.

8. Watanabe H, Okada M, Kaji Y, et al. New response 
evaluation criteria in solid tumours-revised RECIST guideline (version 1.1). Gan To Kagaku Ryoho 2009;36:2495-501.

9. Gundem G, Van Loo P, Kremeyer B, et al. The evolutionary history of lethal metastatic prostate cancer. Nature 2015;520:353-7.

10. Robinson D, Van Allen E, Wu Y, et al. Integrative Clinical Genomics of Advanced Prostate Cancer. Cell 2015;162:454.

11. Shang Z, Cai Q, Zhang M, et al. A switch from CD44+ cell to EMT cell drives the metastasis of prostate cancer. Oncotarget 2015;6:1202-16.

12. Lee JK, Phillips JW, Smith BA, et al. N-Myc Drives Neuroendocrine Prostate Cancer Initiated from Human Prostate Epithelial Cells. Cancer Cell 2016;29:536-47.

13. Akhtar NH, Beltran H, Afzal MZ, et al. Neuroendocrine prostate cancer (NEPC) after androgen deprivation therapy (ADT): Clinical characteristics. J Clin Oncol 2012;30:abstr 190 .

14. Wang HT, Zhang J, Wei S. Histological and molecular phenotype changes of castration-resistant prostate cancer and acquired resistance to hormonal therapy. J Clin Oncol 2015;33:e16006.

15. Heidenreich A, Bellmunt J, Bolla M, et al. EAU guidelines on prostate cancer. Part 1: screening, diagnosis, and treatment of clinically localised disease. Eur Urol 2011;59:61-71.

16. Scher HI, Halabi S, Tannock I, et al. Design and end points of clinical trials for patients with progressive prostate cancer and castrate levels of testosterone: recommendations of the Prostate Cancer Clinical Trials Working Group. J Clin Oncol 2008;26:1148-59.

17. San Francisco IF, Werner L, Regan MM, et al. Risk stratification and validation of prostate specific antigen density as independent predictor of progression in men with low risk prostate cancer during active surveillance. J Urol 2011;185:471-6.

18. Ryu JH, Kim YB, Lee JK, et al. Predictive factors of prostate cancer at repeat biopsy in patients with an initial diagnosis of atypical small acinar proliferation of the prostate. Korean J Urol 2010;51:752-6.

19. Svetec D, McCabe K, Peretsman S, et al. Prostate rebiopsy is a poor surrogate of treatment efficacy in localized prostate cancer. J Urol 1998;159:1606-8.
20. Civantos F, Marcial M, Banks E, et al. Pathology of androgen deprivation therapy in prostate carcinoma. A comparative study of 173 patients. Cancer 1995;75:1634-41.

21. Reuter VE. Pathological changes in benign and malignant prostatic tissue following androgen deprivation therapy. Urology 1997;49:16-22.

22. Petraki CD, Sfikas C. Histopathological changes induced by therapies in the benign prostate and prostate adenocarcinoma. Histol Histopathol 2007;22:107-18.

23. McKay RR, Zukotynski KA, Werner L, et al. Imaging, procedural and clinical variables associated with tumor yield on bone biopsy in metastatic castrationresistant prostate cancer. Prostate Cancer Prostatic Dis 2014;17:325-31.

24. Roodman GD. Mechanisms of bone metastasis. N Engl J Med 2004;350:1655-64.

25. Adami S. Bisphosphonates in prostate carcinoma. Cancer 1997;80:1674-9.

26. Ross RW, Halabi S, Ou SS, et al. Predictors of prostate cancer tissue acquisition by an undirected core bone marrow biopsy in metastatic castration-resistant prostate cancer--a Cancer and Leukemia Group B study. Clin Cancer Res 2005;11:8109-13.

27. Spritzer CE, Afonso PD, Vinson EN, et al. Bone marrow biopsy: RNA isolation with expression profiling in men with metastatic castration-resistant prostate cancer--factors affecting diagnostic success. Radiology 2013;269:816-23.

28. Brown RS, Dogan A, Ell PJ, et al. The comparative values of bone marrow aspirate and trephine for obtaining bone scan-targeted metastases from hormonerefractory prostate cancer. Prostate Cancer Prostatic Dis 2002;5:144-51.

29. Lis E, Bilsky MH, Pisinski L, et al. Percutaneous CTguided biopsy of osseous lesion of the spine in patients with known or suspected malignancy. AJNR Am J Neuroradiol 2004;25:1583-8.

Cite this article as: Liu Z, Wang L, Zhou Y, Wang C, Ma Y, Zhao Y, Tian J, Huang H, Wang H, Wang Y, Niu Y. Application of metastatic biopsy based on "When, Who, Why, Where, How $(4 \mathrm{~W} 1 \mathrm{H})$ " principle in diagnosis and treatment of metastatic castration-resistance prostate cancer. Transl Androl Urol 2021;10(4):1723-1733. doi: 10.21037/tau-21-23 